\author{
Viktor RJABTSIKOV ${ }^{*}$, Anton RASSOLKIN ${ }^{1}$, Vladimir KUTS ${ }^{2}$, \\ Karolina KUDELINA ${ }^{1}$, Toomas VAIMANN ${ }^{1}$, Ants KALLASTE ${ }^{1}$, \\ Andriy PARTYSHEV ${ }^{2}$
}

\title{
PARAMETRIC DIGITAL TWIN OF AUTONOMOUS ELECTRIC VEHICLE TRANSMISSION
}

\begin{abstract}
Variable applications and methodologies are used in the Digital Twin technology. Digital Twin as a trending technology is also a general topic of many industry-oriented research projects. To develop and implement a novel technology, a detailed study of any single part of a system is required. This paper presents a development case study of the parametric Digital Twin of autonomous electric vehicle transmission. Digital Twin combines the advantages of software models and real equipment to reduce total test runs and safe maintenance. The primary duty of the Digital Twin is to allow complete synchronization and connectivity between virtual and real entities. The paper presents a detailed structural description of the virtual entity that considers the parametrization of the transmission.
\end{abstract}

\section{INTRODUCTION}

As traditional design methods and control approaches are often ignored, it is impossible to receive, store, and process real-time data. However, the Digital Twin (DT) concept enables use of system data in many different ways, i.e., not only for detecting anomaly or fault. The advantage of DT is an ability to simulate several modes of system behaviour, trying to reproduce the actual data from the object to predict operation modes that may contain serious failures or just improve the overall performance. The DT concept is based on the idea that a digital informational construct about a physical system could be created as an entity on its own [1].

A distinct advantage of the DT technology is the ability to review detailed data of a single system unit. As a result, DT helps to determine the components that lead to poor performance of a system and thus can be replaced to improve results. That is a merit of essential importance for such a complex system as a propulsion motor-drive system of an electric vehicle that typically includes an electrical machine(s) (motor(s) and/or generator), transmission (reduction gear or gearbox, bearings, etc.), power electronics converter, sensors, and control units. The mechanical part of the electrical drive system causes

\footnotetext{
${ }^{1}$ Department of Electrical Power Engineering and Mechatronics, Tallinn University of Technology, Estonia

${ }^{2}$ Department of Mechanical and Industrial Engineering, Tallinn University of Technology, Estonia

*E-mail: viktor.rjabtsikov@taltech.ee https://doi.org/10.36897/jme/134435
} 
a major proportion of overall faults that are degenerative, i.e., they tend to increase with time [2]. Maintenance of the mechanical part and checking the mechanical operation of devices, verifying proper lubrication, and manually or electrically operating any device that seldom operates should be standard practice [3] for any electrical drive application. DT solution covers a wide range of services, such as efficiency improvement, minimization of failure rates, shortening of development cycles, and opening up new business opportunities [4].

DT, as a virtual entity, must digitally mirror processes occurring within a physical entity. In the real world, multiple physical effects act on an object simultaneously [5], and it is impossible to consider the electrical drive system as an electrical device. There is always a need to consider other phenomena, such as thermal effects or mechanical vibrations. This optimum may need to be reconsidered. DT must reflect effects in different physical domains (electrical, mechanical, thermal). The current study is a part of the research project [6] with the final goal to develop a specialized unsupervised prognosis and control platform for the propulsion drive of an autonomous electric vehicle that may be used for performance estimation, control system tuning, maintenance and diagnostics, and many other services. The main aim of the paper is to present a development process of a parametric DT for an autonomous electric vehicle transmission.

\section{TRANSMISSION PARAMETRIZATION}

\subsection{TEST PLATFORM (ISEAUTO)}

ISEAUTO is the first Estonian self-driving vehicle developed in cooperation between Tallinn University of Technology (TalTech) and several industrial partners. ISEAUTO is a last-mile vehicle designed to operate mainly on the TalTech campus. Therefore, the speed of the car is limited up to $20 \mathrm{~km} / \mathrm{h}$. ISEAUTO self-driving vehicle is an interdisciplinary project that includes contributions from different fields [7]. The mechanical structure is an essential part of a self-driving vehicle; it is to be altered and designed to guarantee dynamical unwavering. ISEAUTO self-driving car was built on a Mitsubishi i-MiEV trolley based on Y4F1 permanent magnet synchronous motor (PMSM) [8]. Electrical motors show better performance at a precise speed and torque [9]. That performance region depends on the type of the motor and is usually chosen based on a certain application. While ISEAUTO is a last-mile vehicle and its speed is limited, the transmission is used to cover the best efficiency region of the propulsion motor. The transmission used in the self-driving vehicle F1E1A (without shifting function) comprises a simple meshing of two pairs of gears as well as a highly reliable differential at an overall reduction ratio of 6.066.

\subsection{D. SCANNING OF TRANSMISSION}

To define the domain to be simulated, specific data is required, such as mechanical and material characteristics, Poisson's ratio (i.e., the negative of the ratio of (signed) transverse strain to (signed) axial strain) and Young's modulus (i.e., a mechanical property that measures 
the stiffness of a solid material), which create the geometry of the component [10]. For the first step of transmission parametrization, the spatial model was created using 3D scanner ATOS II 400. This inspection hardware uses structured light technology, and the measuring frequency is 1.4 mil points per 7 seconds. The resolution is $0.177 \mathrm{~mm}$. For larger object digitalization, markers should be used - those are being installed on the scanning object to merge various scanning pictures later during the post-processing process [11]. The advantages of this scanning technology are: high precision in a short amount of time and technology safe to the eyes. Disadvantages are: system setup is sensible to the ambient light; glance surfaces are impossible to 3D scan, and precision is not enough for small detailed parts with various surface features such as ribs and sharp corners. In related research, due to its high precision for large object inspection, the ATOS 3D scanner was used for digitalization of transmission. As a result, autonomous electric vehicle transmission shown in Fig. 1 is taken as a spatial entity of the DT.

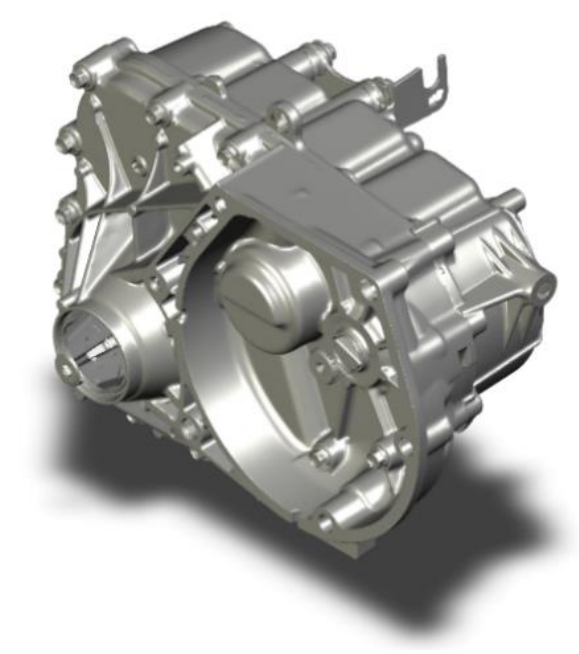

Fig. 1. The parametrization of DT spatial entity of the transmission accomplished with 3D scanner ATOS II 400

F1E1A is a double stage type transmission with four gears, as shown in Fig. 2. The first gear is the pinion gear of the input shaft, which is connected to the rotor of the vehicle traction motor. The second and third pinion gears have a common shaft. The fourth gear is connected to the output shaft and vehicle differential. The parameters of gears are presented in Table 1; all the shafts have the same diameter of $22 \mathrm{~mm}$.

Table 1. Transmission gears

\begin{tabular}{|l|c|c|c|}
\hline Gear & Diameter, $\mathrm{mm}$ & Width, $\mathrm{mm}$ & Teeth number \\
\hline $1^{\text {st }}$ & 58.9 & 27 & 25 \\
\hline $2^{\text {nd }}$ & 93.9 & 251 & 42 \\
\hline $3^{\text {rd }}$ & 56.1 & 32.2 & 18 \\
\hline $4^{\text {th }}$ & 179 & 27.6 & 65 \\
\hline
\end{tabular}




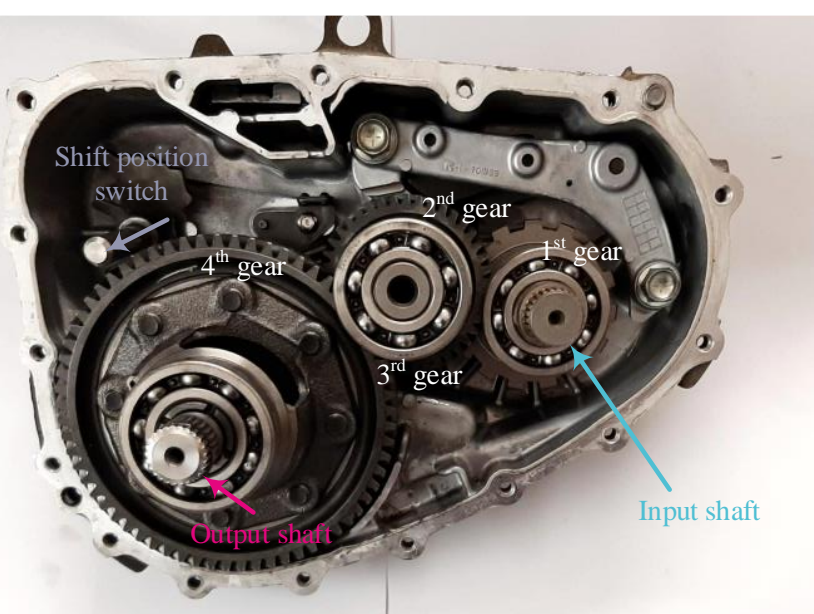

Fig. 2.F1E1A transmission levels and construction

Gear ratio (n) of the transmission can be calculated by the next equation:

$$
n=\frac{n_{4}}{n_{3}} \times \frac{n_{2}}{n_{1}}
$$

where $n_{(1 . .4)}$ is the number of teeth of gear $1 . .4$, respectively. Gear ratio depends on the maximum speed, the wheel radius, the maximum motor speed, and the traction power between the road and the tires. A smaller motor speed relative to the vehicle speed means a lower gear ratio, smaller size, and lower cost [8].

To switch the working modes, a shift position switch is used. While there is no gear shifting mechanism, no actual gear change occurs when the shift position is changed, but the shift position detected by the shift position switch is transmitted to the vehicle control unit, e.g., when the shift position switch is in reverse, the motor revolution is inverted. Regene-rative brake is in the standard model of the standard driving mode of the vehicle. However, the transmission has an additional regenerative brake mode in which a stronger deceleration effect can be obtained by enhancing the regenerative brake effort, and a so-called comfort mode, suitable for driving through the suburbs by decreasing the regenerative brake.

\subsection{THE EFFICIENCY OF THE TRANSMISSION}

Power losses in transmission appear in gears, bearings, and seals. Moreover, auxiliary losses should also be considered. Gear and bearing losses are separated into two different categories: load and no-load dependent losses $[12,13]$, the transmission losses $\left(\Delta p_{m e h}\right)$ are classified in Fig. 3. It is important to note that for nominal power transmission, the load losses of the gear are typically dominant, and in the case of part load and high speed, no-load losses dominate the total losses [14].

$$
\Delta p_{m e h}=\Delta p_{G 0}+\Delta p_{G L}+\Delta p_{B 0}+\Delta p_{B L}+\Delta p_{s}+\Delta p_{a u x}
$$


No-load gear losses are independent of the loading torque. They appear with the rotation of the mechanism since no-load losses may be counted as lubricant losses due to the viscosity and density of the lubricant, internal design of the transmission, and bearings. No-load gear losses rely on the arrangement, size, type, lubricant viscosity, and immersion depth.

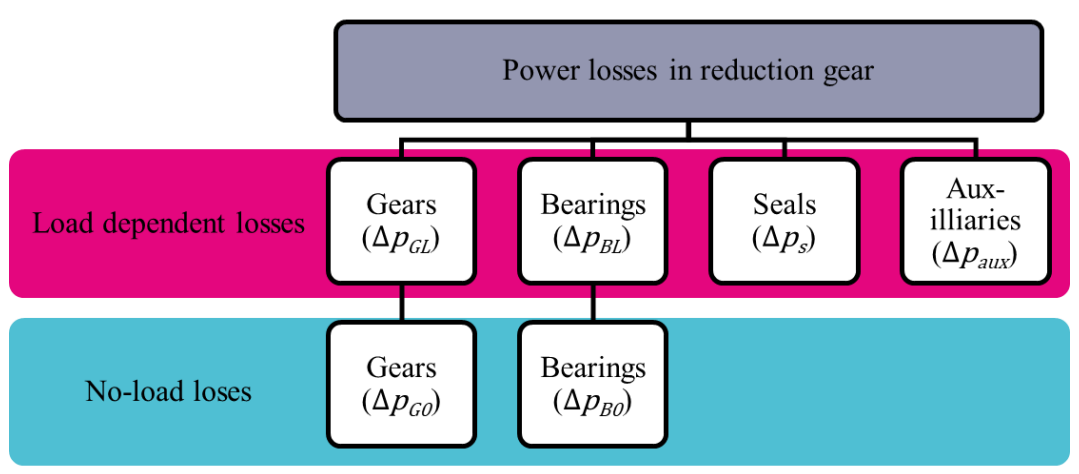

Fig. 3.Power losses in transmission

Load dependent gear losses occur in the contact point of the power transmitting elements. Load dependent gear losses rely on the friction force $\left(F_{R(X)}\right)$ and relative velocity $V_{\text {rel }(X)}$, and follow the basic Coulomb law:

$$
\Delta p_{G L}=F_{R(X)} \cdot V_{r e l(X)}
$$

Commonly, load dependent gear losses that take into account the gear loss factor is expressed as:

$$
\Delta p_{G L}=P_{I N} \cdot H_{V} \cdot \mu_{m Z}
$$

where: $P_{I N}$ is the transmission input power, $H_{V}$ is the gear loss factor and $\mu_{m Z}$ is the coefficient of friction.

Gear loss factor $\left(H_{V}\right)$ is a constant calculated based on the base helix angle, load distribution, the path of contact, and other gear parameters. In their study, C. Fernandes et al. [12] give three different equations for the calculation and propose the calculation method that does not consider the elastic effects of the gears. They show the influence of the calculation of the gear loss factor that is dependent on the geometry of the gear in the prediction of the power loss. The average coefficient of friction $\left(\mu_{m z}\right)$ between the gear teeth for different gear geometries is a complex gain that is usually based on empirical results, and naturally, the results vary for the same operating conditions.

No-load bearing losses highly depend on the bearing type and size (e.g., lowest no-load losses of radial bearings are expected for cylindrical roller bearings [12]), bearing arrangement, lubricant viscosity, and supply. Load dependent bearing losses rely on the size, type, rolling (load) and sliding conditions, and lubricant type. Wimmer et al. [15] provide an analysis of the influence of different bearing types on no-load and load losses. 
Shaft sealing losses are caused by the friction that occurs between the shaft, and its sealing. Shaft sealing losses $\left(\Delta p_{s}\right)$ depend on the shaft diameter $(D)$ and rotational speed $(n)$, and according to $\mathrm{C}$. Changenet et al. [16], these losses can be calculated by:

$$
\Delta p_{s}=7.69 \cdot 10^{-6} \cdot D^{2} \cdot n
$$

Auxiliary losses take into account losses that are hard to determine, e.g., lubricant losses. Transmission requires lubricant to avoid friction and deformations on the gears teeth connection where losses occur when the lubricant is splashed to the pinion, which creates a drag torque on it. Lubricant losses depend on the rotational speed of the pinion, the surface area of the pinion contacts with the lubricant, pitch diameter of the pinion, and density of the lubricant. C. Changenet et al. [16] give an equation to estimate the drag torque that is acting on a pinion as an additional load.

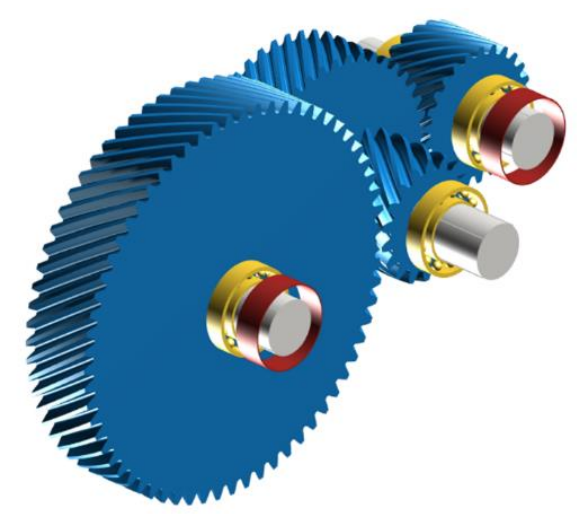

Fig. 4.3D model of a F1E1A gearbox gears

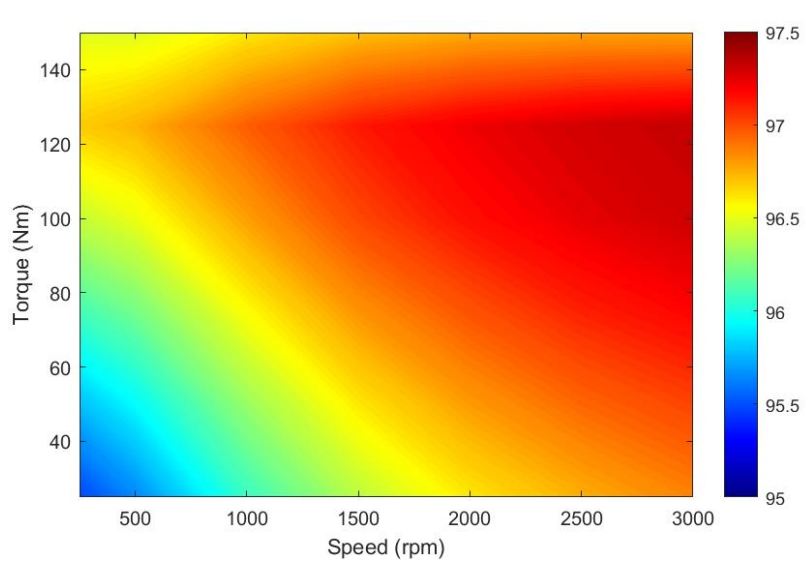

Fig. 5.Efficiency map of a F1E1A gearbox

Various computation tools are used to determine the power losses and build an efficiency map of the mechanical transmission. WTplus software [17] developed in TU Munich is used to calculate the efficiency and the heat management of any manual, automatic, and industrial gearbox. Another software is KISSsoft, with a special template implemented in KISSsys to 
automate the efficiency calculation and thermal rating of a whole gearbox - including gears, shafts, bearings, seals, discs, synchronizers, and other machine elements [18]. By measuring all the gears of the existing F1E1A gearbox, the 3D model was built, which can be observed in Fig. 4. Using the KISSsoft software, we imported a 3D model to the software we used to calculate a gearbox's efficiency. By considering materials, bearings, grease, etc., an efficiency map of a gearbox was calculated and shown in Fig. 5. The torque and speed upper limit is defined by an electric drive's capabilities, which is $150 \mathrm{Nm}$ of torque and $3000 \mathrm{rpm}$ of speed.

\section{DIGITAL TWIN}

DT simulation of the transmission has two key parts, as shown in Fig. 6. A primary simulator is a ROS Node that receives an input consisting of torque $\left(\tau_{i n}\right)$ and angular velocity $\left(\omega_{\text {in }}\right)$ via the ROS Bridge protocol. This input can be supplied by any ROS-based motor controller with an encoder, even a simulated one. The primary simulator then calculates an expected output based on the following equations:

$$
\begin{gathered}
\tau_{\text {out }}=\frac{\tau_{\text {in }}}{n}, \\
\omega_{\text {out }}=\omega_{\text {in }} \cdot n,
\end{gathered}
$$

where $n$ is calculated using formula (1); efficiency simulation of the transmission is one of the main tasks of the primary simulator.

It is achieved by interpolating the efficiency of the transmission at a specific torque and angular velocity based on an empirically (generated, gathered, collected, created) efficiency map. Afterward, the resulting torque $\left(\tau_{\text {out }}\right)$, angular velocity $\left(\omega_{\text {out }}\right)$ and efficiency are published as a ROS topic for further use by the second part of the DT - 3D Visualizer.

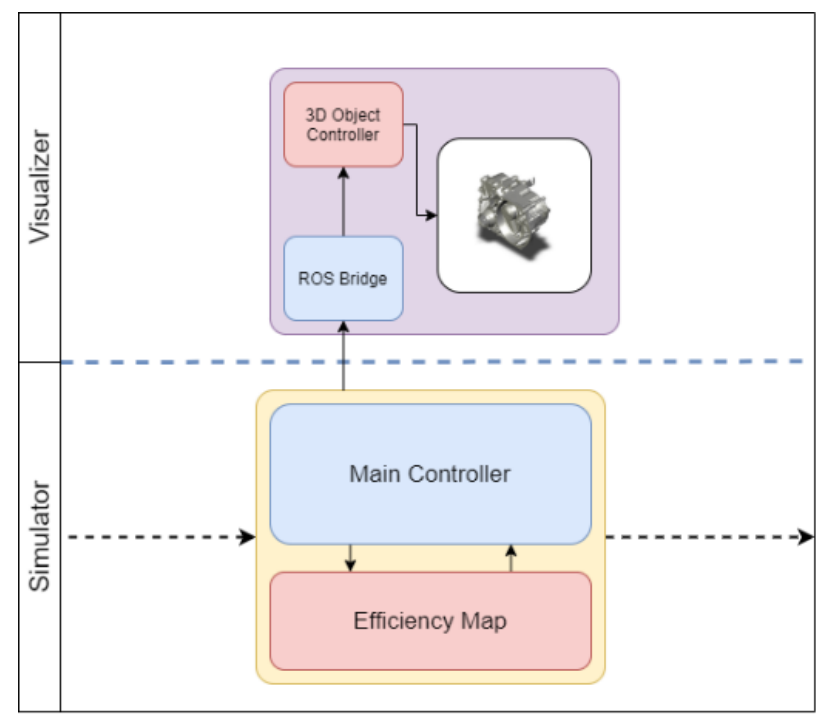

Fig. 6. The operational architecture of the transmission Digital Twin 
Both simulation and visualization of the transmission are based on the framework created for the DT of the load motor [19]. They work and communicate in the same way via the ROS Bridge; however, visualization of the transmission does not provide feedback to the simulation because there is no closed-loop speed controller that requires feedback. The transmission does not drive itself. It only converts the inputs it is given by the rest of the system.

Visualizer is responsible for providing a 3D representation of the behaviour of the DT, Unity 3D capture of the transmission shown in Fig. 7. It is achieved by taking the data published by the primary simulator and feeding it to the 3D model controller that recalculates states of each 3D object and makes the transmission's CAD model appear on the screen as the real transmission would in any given conditions.

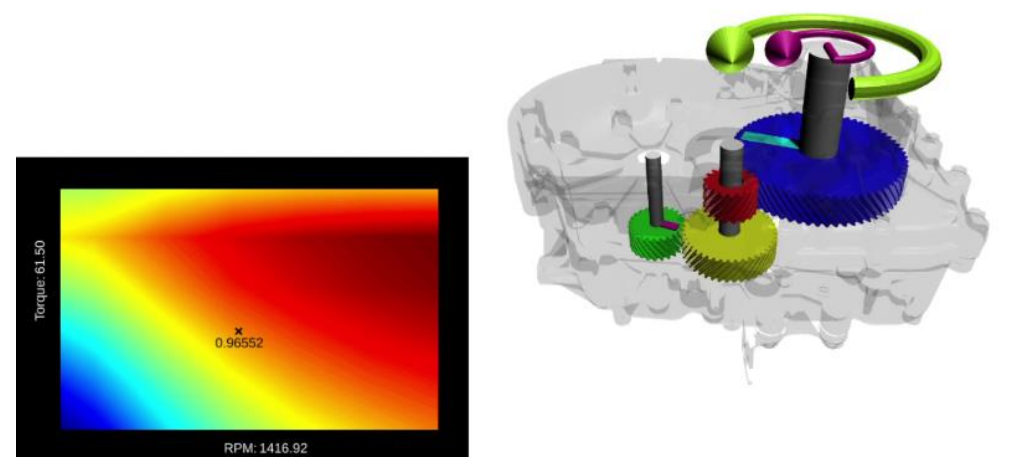

Fig. 7.Unity 3D live visualization of transmission

Digital Twin of the gearbox creation process architecture is presented in Fig. 8. 3D scan of the gearbox is required to determine mechanical and material characteristics. Obtained data is used to create a spatial model of the gearbox, which later can be used in the simulator. The simulator is consisting of a middle-layer, in our case is ROS, and data is taken from he cloud server. Finally, the 3D visualizer block uses a Unity 3D engine and demonstrates the gearbox work.

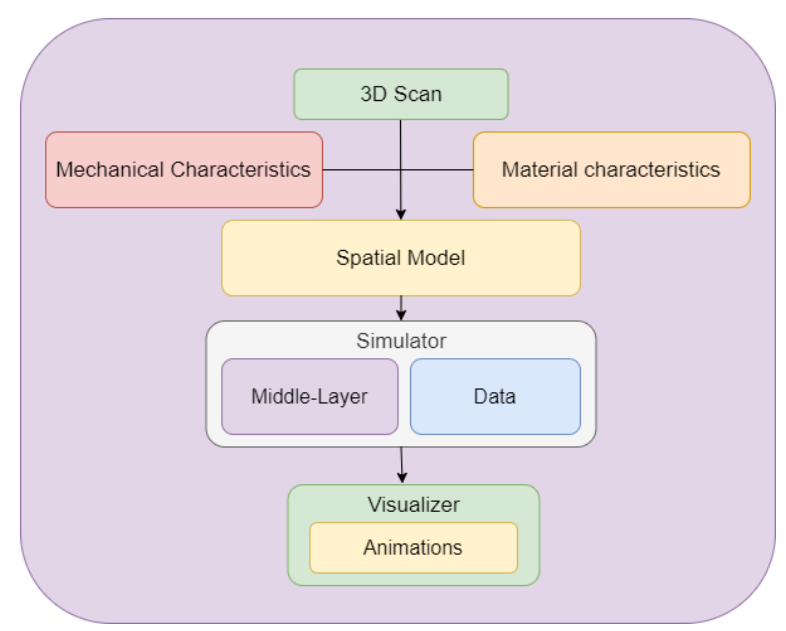

Fig. 8. Process architecture 


\section{CONCLUSION}

The transmission parametrization process starts with 3D scanning of the studied object, followed by the prescription of gears and efficiency calculation. The spatial model created in the Unity 3D real-time development platform is supplied with proper inputs and outputs to connect the physical model. Such a physical model that takes into account the efficiency of autonomous electric vehicle transmission serves as a perfect tool to construct the DT for the mechanical part of the whole propulsion motor-drive system. The concept of Virtual Sensors based on the developed DT may be introduced. The overall performance of the current autonomous electric vehicle may be studied and improved based on the developed DT.

The future transmission DT development will include combining transmission DT with the DTs of the other parts of the propulsion drive of autonomous electric vehicles (motor, controller, etc.). Moreover, transmission DT will be synchronized with the real transmission on the developed test bench [20] and will be trained to provide a bridge between real and virtual entities of the system. Artificial Intelligence (AI)-based system will be developed to be able to diagnose and predict the condition of the device to timely provided services (incl. future services schedules), data about unusual situations and other circumstances based on the historical data of the propulsion drive system and the physical/mathematical model (DT).

\section{ACKNOWLEDGMENTS}

The visualization of real-time operation of the considered example one can see in the following URL: https://youtu.be/RggHNE3hvOo Source code of developed DT is available on: https://github.com/TalTech-PSG453/ gearbox_dt.git.

\section{REFERENCES}

[1] GRIEVES M., VICKERS J., 2016, Digital Twin: Mitigating Unpredictable, Undesirable Emergent Behavior in Complex Systems Excerpt, Transdisciplinary Perspectives on Complex Systems, August, Springer International Publishing, 23, 889-896.

[2] ASAd B., VAIMANN T., RASSÕLKIN A., KALLASTE A., BELAHCEN A., 2019, A Survey of Broken Rotor Bar Fault Diagnostic Methods of Induction Motor, Electr. Control Commun. Eng., 14/2, 117-124, doi: 10.2478/ ecce-2018-0014.

[3] IEEE Std 3006.3TM, 2017, Recommended Practice for Determining the Impact of Preventative Maintenance on the Reliability of Industrial and Commercial Power Systems, doi: 10.1201/9780429287015-5.

[4] BEVILACQUA M., 2020, Digital Twin Reference Model Development to Prevent Operators' Risk in Process Plants, Sustain, 12/3, 1-17, doi: 10.3390/su12031088.

[5] FLORKOWSKI M., SZARY D., MOGLESTUE A., 2019, Digital Twins and Simulations: World of Simulation, ABB Rev., 2, 8-13.

[6] RASSÕLKIN A., VAIMANN T., KALlASTE A., KUTS V., 2019, Digital Twin for Propulsion Drive of Autonomous Electric Vehicle, $60^{\text {th }}$ International Scientific Conference on Power and Electrical Engineering of Riga Technical University (RTUCON).

[7] RASSÕLKIN A., SELL R., LEIER M., 2018, Development Case Study of the First Estonian Self-Driving Car, ISEAUTO, Electr. Control Commun. Eng., 14/1, 81-88, doi: 10.2478/ecce-2018-0009.

[8] RASSÕLKIN A., 2018, Propulsion Motor Drive Topology Selection for Further Development of ISEAUTO SelfDriving Car, 59 ${ }^{\text {th }}$ International Scientific Conference on Power and Electrical Engineering of Riga Technical University (RTUCON), doi: 10.1109/RTUCON.2018.8659887. 
[9] RASSÕLKIN A., 2020, Life Cycle Analysis of Electrical Motor Drive System Based on Electrical Machine Type, Proc. Est. Acad. Sci., 69/2, 162-177, doi: 10.3176/proc.2020.2.07.

[10] REVETRIA R., TONELli F., DAMIANI L., DEMARTINI M., BISIO F., PERUZZO N., 2019, A Real-Time Mechanical Structures Monitoring System Based on Digital Twin, IOT and Augmented Reality, Simulation Series, 51/1, doi: 10.23919/SpringSim.2019.8732917.

[11] KUTS V., TAHEMAA T., OTTO T., SARKANS M., LEND H., 2016, Robot Manipulator Usage for Measurement in Production Areas, Journal of Machine Engineering, 16/1, 57-67.

[12] FERNANDES C.M.C.G., MARQUES P.M.T., MARTINS R., SEABRA J.H.O., 2015, Influence of Gear Loss Factor on the Power Loss Prediction, Mechanisms and Machine Science, 24, 799-806, doi: 10.1007/978-3-31909411-3_84.

[13] HINTERSTOIßER M., HÖHN B.R., MICHAELIS K., 2009, Optimization of Gearbox Efficiency, Goriva i Maz. Časopis. za Tribol. Teh. Pod. i Primjen, Tekućih i Plinovitih Goriva i Inžinjerstvo Izgaranja, 48/4, 462-480.

[14] MICHAELIS K., HÖHN B.R., HINTERSTOIßER M., 2011, Influence Factors on Gearbox Power Loss, Ind. Lubr. Tribol., 63/1, 46-55, doi: 10.1108/00368791111101830.

[15] WIMMER A., SALZGEBER K., HASLINGER R., 2003, WP1 - Analysis of Minimum Oil Requirements Considering Friction in Gears and Engines, Final Report Oil-free Powertrain, EU Project Contract No: IPS-2001CT-98006.

[16] CHANGENET C., PASQUIER M., 2002, Power Losses and Heat Exchange in Reduction Gears: Numerical and Experimental Results, VDI Berichte, 2/1665, 603-613.

[17] Gear Research Centre (FZG), https://www.mw.tum.de/en/fzg/research/, (accessed Oct. 28, 2020).

[18] Simulation and Computer Programs - Department of Mechanical Engineering, https://www.mw.tum.de/en/fzg/ research/simulation-and-computer-programs/, (accessed Oct. 28, 2020).

[19] LANGHART J., BAE I., 2014, How to Get Most Realistic Efficiency Calculation for Gearboxes? Int. Gear Conf. $26^{\text {th }}-28^{\text {th }}$ August, Lyon, 869-878, doi: 10.1533/9781782421955.869.

[20] RASSÕLKIN A., RJABTŠIKOV V., VAIMANN T., KALLASTE A., KUTS V., PARTYSHEV A., 2020, Digital Twin of an Electrica Motor Based on Empirical Performance Model (Accepted), Proceeding of XI International Conference on Electrical Power Drive Systems (ICEPDS). 